\title{
Hospitality Training Bagi Para Pengelola Homestay di Desa Liang Ndara Kabupaten Manggarai Barat
}

\author{
Gregorius A. Berybe ${ }^{1}$, Elisabet Oktaviani Hanggu ${ }^{2}$, Maria B.R. Welalangi ${ }^{3}$, Novita ${ }^{4}$ \\ ${ }^{1}$ Politeknik eLBajo Commodus, Labuan Bajo, Indonesia email: gregberybe@poltekelbajo.ac.id \\ ${ }^{2}$ Politeknik eLBajo Commodus, Labuan Bajo, Indonesia, email: elisabetoktaviani@poltekelbajo.ac.id \\ ${ }^{3}$ Politeknik eLBajo Commodus, Labuan Bajo, Indonesia, email: maria.wellalangi@poltekelbajo.ac.id \\ ${ }^{4}$ Politeknik eLBajo Commodus, Labuan Bajo, Indonesia, email: novita@ poltekelbajo.ac.id
}

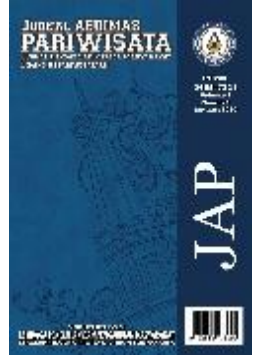

\begin{tabular}{|c|c|}
\hline Informasi artik & \\
\hline $\begin{array}{l}\text { Sejarah } \\
\text { artikel }\end{array}$ & \\
\hline Diterima & : 4 Desember 2020 \\
\hline Revisi & : 19 Desember 2020 \\
\hline Dipublikasikan & : 1 Januari 2021 \\
\hline
\end{tabular}

Kata kunci:

Hospitality training

Homestay

Desa wisata

\begin{abstract}
ABSTRAK
Kegiatan pengabdian kepada masyarakat ini bertujuan untuk meningkatkan kapasitas Sumber Daya Manusia (SDM) pengelola homestay di Desa Liang Ndara Kabupaten Manggarai Barat. Kegiatan pengabdian ini meliputi pelatihan terkait sanitasi dan hygene, service quality, public speaking, dan Bahasa Inggris. metode yang digunakan dalam kegiatan ini adalah metode edukatif yakni mencakup kegiatan sosialisasi, pelatihan, dan pendampingan sebagai sarana transfer ilmu pengetahuan dan pendidikan untuk pemberdayaan pengelola homestay di Desa Liang Ndara. Kegiatan ini menghasilkan kemajuan yang pesat bagi para pengelola homestay terutama pemahaman mengenai sanitasi dan hygene, food and beverage product, food and beverage service, public speaking, dan Bahasa Inggris. Para pengelola homestay siap menerapkan ilmu yang telah mereka dapatkan untuk meningkatkan kualitas pelayanan di homestay.

ABSTRACT

Hospitality Training for Homestay Managers in Liang Ndara Village, West Manggarai Regency

This community service activity aims to increase the capacity of the Human Resources (HR) manager of the homestay in Liang Ndara Village, West Manggarai Regency. This service activity includes training related to sanitation and hygiene, food and beverage products, public speaking, and English language training. The method used in this activity is an educational method, which includes socialization, training, and assistance as a means of transferring knowledge and education for empowering homestay managers in Liang Ndara Village. This activity resulted in rapid progress for homestay managers, especially an understanding of sanitation and hygiene, food and beverage products, public speaking, and English. Homestay managers are ready to apply the knowledge they have gained to improve the quality of service at the homestay.
\end{abstract}

Keywords:

Hospitality training,

Homestay,

Tourism village

\section{Pendahuluan}

Desa Liang Ndara merupakan salah satu desa yang berlokasi di Kecamatan Mbeliling, Kabupaten Manggarai Barat. Desa ini dapat ditempuh dengan menggunakan kendaraan roda dua maupun roda empat dengan lama pejalanan 30 sampai 45 menit. Desa ini dikenal karena memiliki wisata budaya seperti tarian caci tarian rangkuk alu, tarian ako mawo dan beberapa tarian lain yang dapat ditampilkan kepada para wisatawan. Setelah ditelusuri desa ini ternyata memiliki beberapa sanggar yang dikelola dengan baik oleh masyarakat desa dan sering tampil dalam acara-acara daerah maupun nasional. Secara geografis Desa Liang Ndara adalah kawasan dataran tinggi, perbukitan, dan lereng dari Gunung Mbeliling. Gunung Mbeliling adalah kawasan resapan air di dataran tinggi Manggarai yang merupakan sumber mata air bagi kawasan sekitarnya termasuk kota Labuan Bajo. Secara administratif, desa ini terdiri dari 3 (tiga) dusun yaitu dusun Liang Niki I (Melo), Pate Kantor (Cecer), dan Liang 
Niki II (Mamis). Secara permukiman, desa Liang Ndara terdiri 3 (tiga) kampung, yaitu: Melo, Cecer, dan Mamis yang dengan pusat desa terletak di Melo.

Pada bulan November 2020 tercatat kurang lebih 25 homestay yang dikelola mandiri oleh masyarakat Desa Liang Ndara. Masyarakat menyadari bahwa prasarana wisata merupakan sumber daya buatan manusia yang selayaknya harus tersedia pada destinasi wisata. Homestay memampukan wisatawan untuk memiliki tempat berteduh dengan suasana yang menyerupai rumah selama mereka menghabiskan waktu di tempat tujuan tertentu. Hal ini memungkinkan wisatawan untuk semakin mengenal tempat setempat atau bahkan meningkatkan keterampilan penguasaan atas bahasa setempat. Sehingga melalui cara ini, para wisatawan mendapatkan pilihan selain tinggal di hotel, guest house atau backpackers. Memiliki sebuah homestay dapat memberikan pengalaman yang $\mathrm{m}$ baik kepada pemilik homestay maupun kepada wisatawan. Homestay di Desa Wisata memungkinkan para tamu untuk melihat dan merasakan sekilas kehidupan sehari-hari warga desa yang berbeda dengan interaksi pariwisata konvensional (Kontogeorgopoulos et al., 2015). Cara bisnis ini dapat membantu pemilik homestay menghasilkan uang tambahan, bertemu dengan orang-orang yang menarik, dan mereka juga dapat berbagi tradisi dan budaya yang mereka banggakan kepada para pengunjung. Hal ini juga dapat meningkatkan pengalaman para wisatawan ditempat wisata mereka. Tim dosen DIV Pengelolaan Perhotelan melakukan survey awal dengan metode penyebaran kuesioner dan group discussion tokoh masyarakat dan Kepala Desa Liang Ndara untuk mengetahui sejauh mana pemahaman pengelola homestay. Berdasarkan hasil kunjungan dan diskusi tersebut ditemukan beberapa kendala yang dihadapi masyarakat Desa Liang Ndara dalam pengelolaan homestay yaitu : 1). Minimnya pengetahuan pengelola homestay terkait pelayanan kepada wisatawan, 2). Kurangnya pengetahuan berkomunikasi yang baik terutama dalam Bahasa Inggris, 3). Rendahnya pengetahuan mengenai sanitasi dan hygiene. Melalui survey singkat tersebut, dapat disimpulkan bahwa permasalahan yang dihadapi para pengelola homestay di Desa Liang Ndara pada umumnya adalah terkait peningkatan kapasitas sumber daya manusia. Wisata homestay menekankan pada produk ekowisata serta community based tourism di mana pengunjungnya tinggal bersama keluarga asuh dan terlibat dengan aktivitas normal sehari-hari untuk merasakan gaya hidup dan budaya lokal (Ismail et al., 2016). Pengelolaan Sumber Daya Manusia, Kelembagaan, dan data mengacu Wang (2012) dan ASEAN Secretariat (2016) merupakan hal penting yang harus dilakukan dalam menjalankan bisnis homestay selain, fisik dan lingkungan serta promosi.

Kegiatan Pengabdian kepada Masyarakat yang akan dilakukan oleh tim dosen prodi DIV Pengelolaan Perhotelan ini merupakan salah satu wujud nyata bantuan yang diberikan perguruan tinggi Politeknik Elbajo Commodus untuk membantu mewujudkan visi Desa Liang Ndara yaitu "Terwujudnya Masyarakat Desa Liang Ndara yang Cerdas, Partisipatif, Mandiri, Utuh, dan Sejahtera." Solusi yang diberikan untuk dapat mengurangi permasalahan pengelolaan homestay di Desa Liang Ndara dapat diuraikan sebagai berikut. 1). Pelatihan Bahasa Inggris bagi para pengelola homestay. 2). Pelatihan public speaking dalam melayani kolega dan pelanggan. 3). Pelatihan sanitasi dan hygene dalam pengelolaan homestay dan desa wisata. 4). Pelatihan food and beverage service bagi pengelola homestay. Adapun pemahaman atau materi-materi Bahasa Inggris yang diajarkan pada hospitality training bagi pengelola homestay desa Liang Ndara yaitu welcoming guest, reservation, local attraction, local activities, local commodities, dan types of expression. Materi disesuaikan dengan kebutuhan nyata pelaku pariwisata dalam hal ini para pengelola homestay yang ada di desa Liang Ndara. Topik-topik yang ada, diupayakan dapat memberikan gambaran dan pemahaman kepada para pengelola homestay terkait bagaimana menerima tamu yang datang ke desa Liang Ndara baik tamu lokal maupun mancanegara dengan menggunakan Bahasa Inggris. Selain itu, mereka juga diajarkan bagaimana melakukan reservasi ketika tamu memesan homestay untuk menginap, bagaimana menjelaskan atraksi lokal dan komoditas lokal yang ada di desa Liang Ndara menggunakan Bahasa Inggris dan juga berbagai ungkapan seperti handling guest complaint, helping hand dan gratitude dalam Bahasa Inggris. Pelatihan dan pendampingan Bahasa Inggris diharapkan bisa membantu masyarakat setempat dalam hal ini para pengelola homestay untuk lebih siap menyambut tamu-tamu yang datang berwisata ke desa Liang Ndara dan lebih percaya diri ketika berkomunikasi menggunakan Bahasa Inggris dengan tamu asing. Pemahaman mengenai public speaking diajarkan kepada para pengelola homestay agar mereka dapat berkomunikasi dengan baik, benar, dan santun terhadap tamu. Komunikasi yang baik dengan kolega dan tamu dapat menciptakan kesan positif dan 
kedatangan yang berulang dari tamu. Karyawan yang bekerja dalam bidang pariwisata perhotelan memerlukan percakapan dan diskusi dengan staf dan pelanggan. Keterampilan antar pribadi yang utama dibutuhkan, meliputi: penampilan diri yang baik, kemampuan berkomunikasi dengan jelas, inisiatif dalam berinteraksi social, dan kerja sama (Suherian dan Budiono, 2013: 160). Pengelola homestay di Desa Liang Ndara harus mampu berkomunikasi dengan baik sehingga kualitas pelayanan homestay juga menjadi baik. Pemahaman yang diberikan mengenai kualitas pelayanan dalam homestay meliputi konsistensi, responsivitas, kompetensi, aksesibilitas, kesopanan, komunikasi, kredibilitas, keamanan dan pemahaman mengenai kebutuhan dan keinginan pelanggan. Sanitasi dan hygiene adalah element penting dalam pengelolaan homestay. Kebersihan lingkungan dan pengelola homestay merupakan standar homestay berdasarkan (Asean Homestay Standard, n.d.). Rejeki, (2015) menjelaskan Sanitasi adalah segala upaya pencegahan penyakit yang menitikberatkan pada upaya menjaga kesehatan lingkungan manusia. Fokus sanitasi adalah kebersihan lingkungan. Sedangkan Hygiene adalah kebersihan sebagai proses bagaimana orang menjaga dan melindungi kesehatan diri (Wahyunanto, 2018). Kriteria-kriteria dalam pelayanan tersebut penting diperhatikan agar memenuhi ekspektasi pelanggan yang pada akhirnya berimbas pada loyalitas pelanggan. Apabila pelanggan loyal maka dengan sendirinya profit yang diperoleh pemilik homestay di Desa Liang Ndara pun meningkat.

\section{Metode}

Metode yang digunakan dalam kegiatan Pengabdian kepada Masyarakat ini adalah metode edukatif. Metode edukatif mencakup kegiatan sosialisasi, pelatihan, dan pendampingan sebagai sarana transfer ilmu pengetahuan dan pendidikan untuk pemberdayaan masyarakat. Sosialisasi awal kegiatan dilakukan sebanyak dua kali. Pertama, sosialisasi dilakukan kepada Kepala Desa Liang Ndara dan tokoh masyarakat Desa Liang Ndara. Kedua, sosialisasi dilakukan kepada masyarakat Desa Liang Ndara. Sosialisasi ini bertujuan untuk mengetahui kendala, memberikan solusi terhadap masalah yang dihadapi mitra dan menyampaikan rencana pendampingan oleh tim dosen Politeknik eLBajo Commodus. Pengumpulan data terkait dengan analisis permasalahan yang dihadapi mitra dilakukan juga dengan observasi dan wawancara pihak-pihak terkait.

Kegiatan dilakukan 2 tahap dimana tahap 1 adalah Seminar terkait Hospitality Training bagi pengelola homestay. Seminar ini dilakukan untuk memberikan gambaran awal pentingnya hospitality dalam industri pariwisata. Tahap 2 adalah pendampingan selama 3 bulan (10 pertemun). Metode pendampingan dipilih agar materi yang disampaikan lebih mendalam dan berdasarkan komunikasikomunikasi umum yang sering terjadi dalam lingkup homestay. Selama pendampingan, juga diberikan materi-materi tambahan seperti psikologi pelayanan, pentingnya sanitasi hygiene serta pelatiha pembuatan makanan dan minuman lokal dengan bahan dasar nanas yang adalah hasil desa Liang Ndara. Target dari kegiatan ini adalah adanya gambaran akan pentingnya hospitality dan didukung kemampuan komunikasi umum sehari-hari dalam ruang lingkup homestay.

\section{Hasil dan Pembahasan}

Pendampingan terkait hospitality training bagi pengelola homestay di Desa Liang Ndara ini berjalan dengan baik dan lancar. Hasil kegiatan sangat membantu para pengelola homestay dalam menjalankan bisnis homestay mereka. Pendampingan yang dilakukan meliputi : 1). Pendampingan Bahasa Inggris 2). Pengolahan makanan dan minuman lokal, Sebagai penghasil nanas, pendampingan pembuatan makanan lokal seperti wajik dan selai nanas serta minuman Pina Colada (alkohol dan non alkohol). 3) Standard pelayanan yang berkualitas. Hasil kegiatan ini dapat dideskripsikan sebagai berikut. Pertama, adanya peningkatan penguasaan Bahasa Inggris dalam berkomunikasi para pengelola homestay di Desa Liang Ndara. Mereka sangat mengharapkan keterlibatan Politeknik El Bajo Commodus dalam pendampingan Bahasa Inggris terus dilanjutkan sampai mereka dapat fasih berbahasa Inggris. Masyarakat menyadari bahwa komunikasi menggunakan Bahasa Inggris adalah suatu kemampuan yang harus dimiliki oleh seorang pengelola homestay untuk dapat berkomunikasi secara efektif dengan kolega dan pelanggan. Kedua, terkait materi pelayanan standar yang berkualitas. Masyarakat menyadari betapa pentingnya kebersihan diri dan kebersihan lingkungan dalam 
pengelolaan homestay. Masyarakat senantiasa menjaga kebersihan diri dan lingkungan homestay mulai dari dalam kamar, rumah, kamar mandi, dan lingkungan tempat tinggal. Para pengelola homestay disarankan untuk menyiapkan tempat sampah yang memenuhi standar yang ditetapkan pemerintah dalam pengelolaan homestay. Ketiga, terkait dengan pengolahan makanan dan minuman lokal. Pengelola homestay dapat membuat menu tambahan untuk dapat disajikan kepada tamu homestay. Menu tersebut diolah dari SDA local yang banyak ditemukan di desa mereka. Berikut ini adalah rangkaian materi Bahasa Inggris yang telah diberikan kepada para pengelola homestay.

Tabel 1 Materi Kegiatan Pendampingan

\begin{tabular}{|c|c|c|}
\hline No & Materi Pendampingan & Sub Materi Pendampingan \\
\hline 1 & Psikologi Pelayanan & $\begin{array}{l}\text { Personal Grooming, Personal Gesture, } \\
\text { Speaking Confidently }\end{array}$ \\
\hline 2 & Sanitasi \& Hygiene & Personal Hygiene, Personal Apperience \\
\hline 3 & Welcoming guest & $\begin{array}{l}\text { Greeting the guest, Introduction, Welcoming } \\
\text { guest entering Homestay" }\end{array}$ \\
\hline 4 & $\begin{array}{l}\text { English for Specific Purposes } \\
\text { : Showing Room" }\end{array}$ & Showing room, Rooms facilities, House rules \\
\hline 5 & Local product & Pinacolada, (alcohol dan non alcohol) \\
\hline 6 & $\begin{array}{l}\text { English for Specific Purposes: } \\
\text { front office }\end{array}$ & Terminologies in front office \\
\hline 7 & $\begin{array}{l}\text { English for Specific Purposes: } \\
\text { Reservation }\end{array}$ & $\begin{array}{l}\text { Making and practice dialogue related to } \\
\text { front office }\end{array}$ \\
\hline 8 & Local product & selai nanas, wajik nanas. \\
\hline 9 & $\begin{array}{l}\text { English for Specific Purposes } \\
: F \& B \text { Service }\end{array}$ & Terminologies in $F \& B$ Service \\
\hline 10 & $\begin{array}{l}\text { English for Specific Purposes } \\
: F \& B \text { Service }\end{array}$ & $\begin{array}{l}\text { Making and practice dialogue related to } \\
F \& B \text { Service }\end{array}$ \\
\hline
\end{tabular}

Sumber: Data Internal Prodi DIV Pengelolaan Perhotelan Politeknik Elbajo Commodus

Materi-materi pelatihan di atas menjadi bagian pokok pendampingan bagi para pengelola homestay di desa Liang Ndara. Setiap kegiatan para peserta diberikan modul latihan yang menjadi pedoman kegiatan berjalan. Dalam modul tersebut terdapat beberapa percakapan, daftar kosa kata yang akan digunakan beserta cara membacanya, serta beberapa catatan budaya. Percakapan dalam Bahasa Inggris akan dipelajari bersama kemudian dilakukan roleplay antar peserta. Untuk mendukung metode roleplay, lokasi yang digunakan adalah homestay sekitar sehingga menguatkan unsur Tim dosen akan memberikan masukan dan tambahan terkait kemajuan yang diberikan oleh peserta. Daftar kosa kata memudahkan peserta untuk melihat kata yang ingin diucapkan sewaktu-waktu dalam berdialog. Peserta pendampingan sangat antusias dalam mengikuti kegiatan ini. Masyarakat menyadari bahwa peningkatan kapasitas SDM memang menjadi hal penting yang harus diwujudkan. Mereka sangat merasa senang akan kehadiran pihak-pihak yang turut serta membantu dalam mewujudkan hal tersebut dalam hal ini adalah kampus Politeknik eLBajo Commodus melalui Program Studi DIV Pengelolaan Perhotelan. Kemajuan yang ditunjukan mulai dialami para peserta secara perlahan. Hal ini ditunjukan dengan sikap peserta yang mulai bisa berbahasa Inggris dengan mahasiswa dan tim dosen misalnya menyapa, memperkenalkan diri dan menanyakan kabar sebelum kegiatan pendampingan dimulai. Selama pendampingan juga ditemui kendala-kendala seperti jumlah peserta yang hadir tidak konsisten, jadwal kegiatan bersamaan dengan kegiatan di desa, dan daya tangkap materi yang berbeda dikarenakan usia peserta yang sebagia besar diatas 40 tahun. Berikut adalah beberapa dokumentasi kegiatan yang telah dilakukan : 


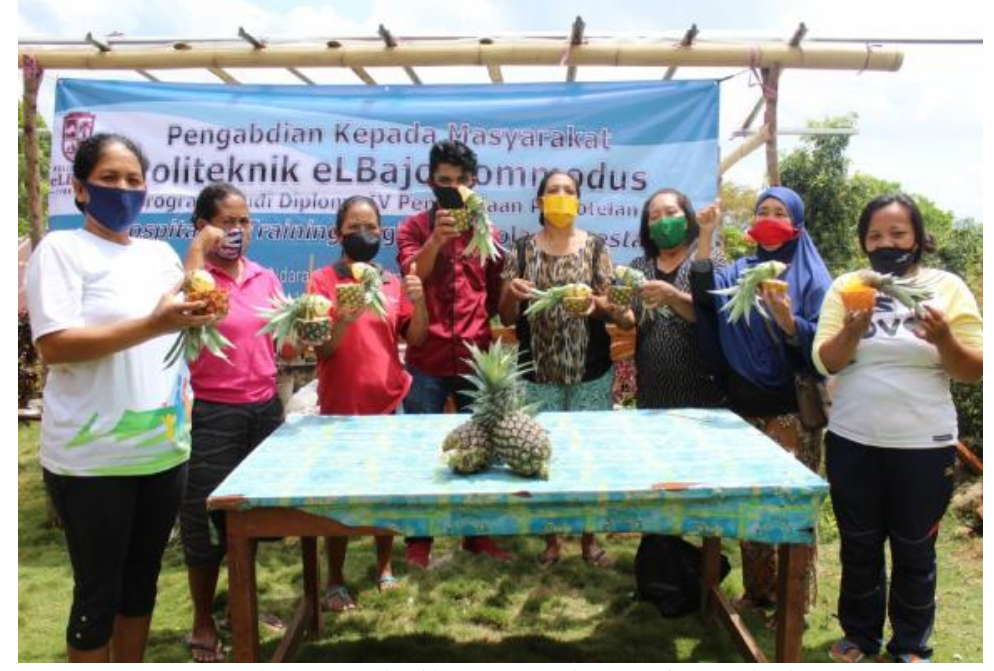

Gambar 1 pelatihan membuat pinacolada

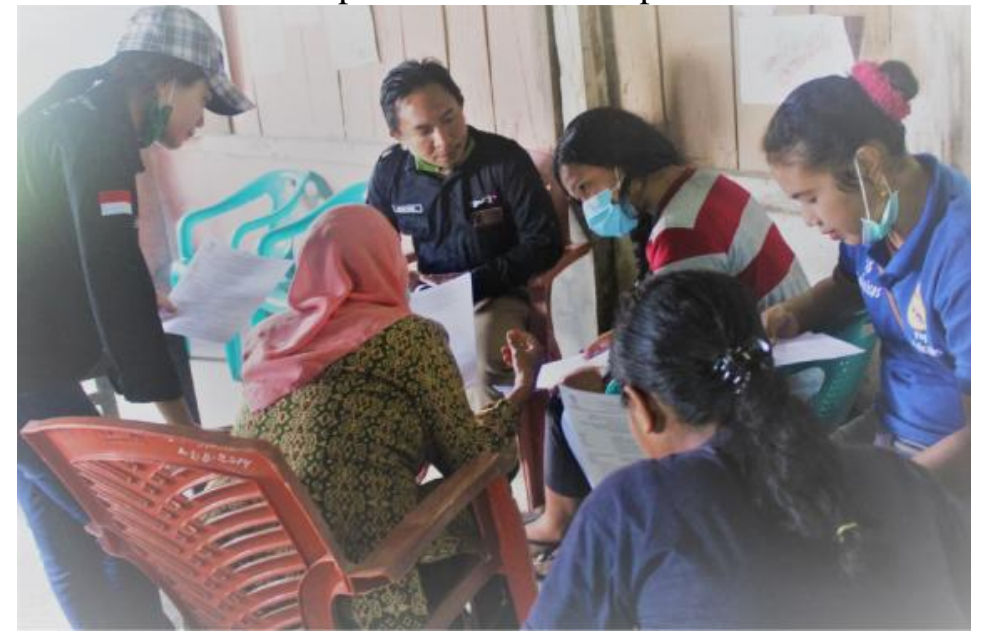

Gambar 2 Pelatihan Bahasa Inggris

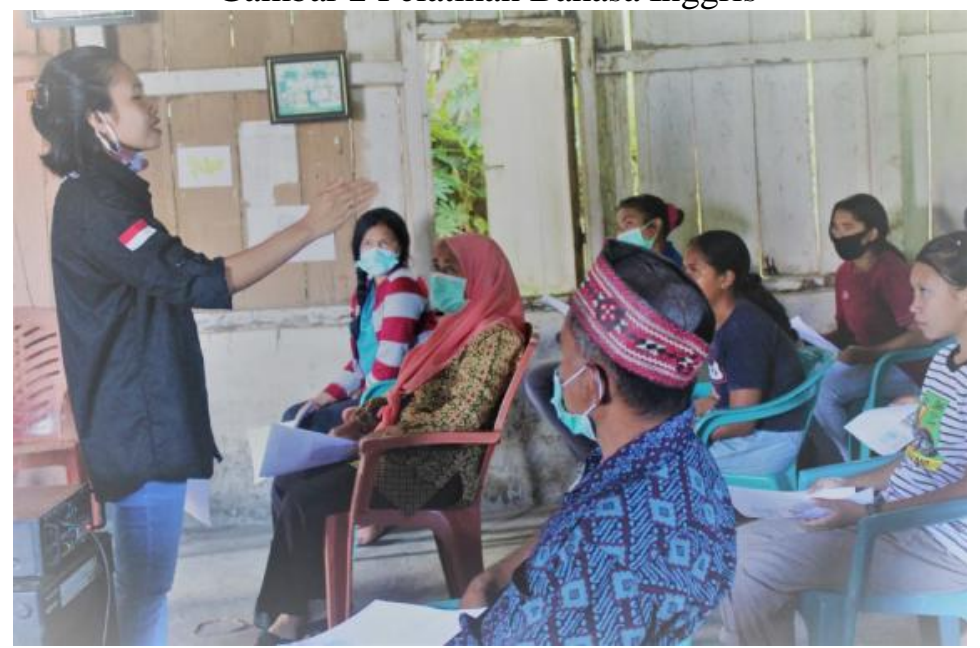

Gambar 3 pelatihan Bahasa Inggris 


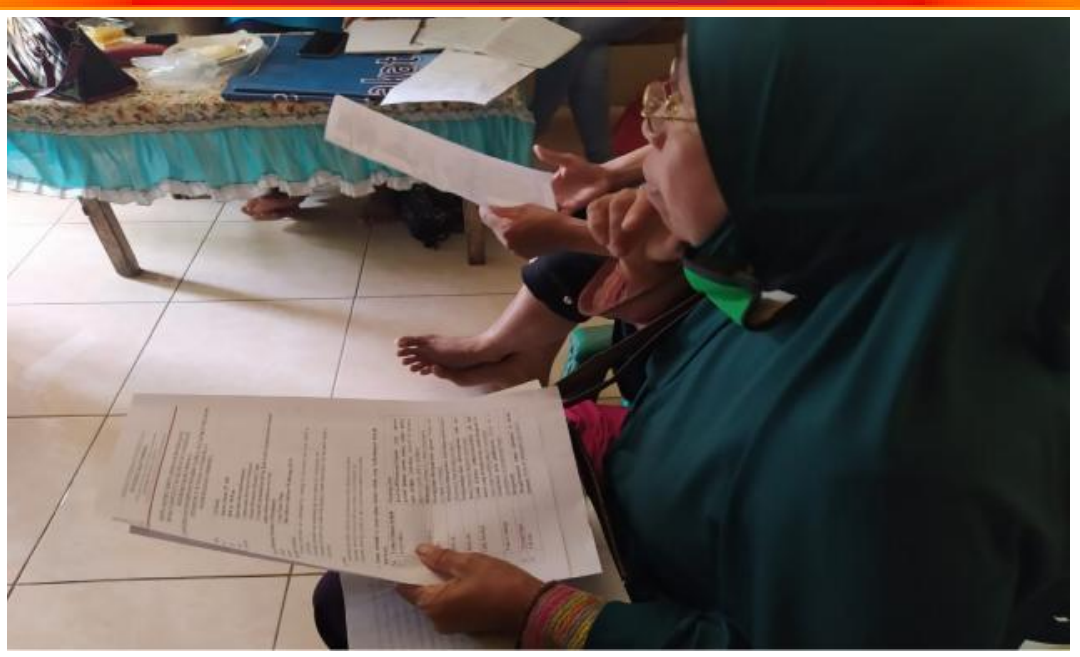

Gambar 4 pelatihan Bahasa Inggris

Kegiatan pendampingan ini merupakan solusi yang diberikan oleh tim dosen terhadap masalah yang dihadapi oleh para pengelola homestay di Desa Liang Ndara. Para peserta sangat antusias dalam mengikuti kegiatan pelatihan Bahasa Inggris ini. Rentang usia peserta yang mengikuti kegiatan pelatihan ini didominasi oleh peserta dengan usia 40 tahun ke atas. Tim dosen memberikan treatment khusus sehingga tujuan dari kegiatan pelatihan Bahasa Inggris ini dapat tercapai. Para peserta mengatakan bahwa mereka mengalami kesulitan jika harus belajar menulis kata-kata dalam Bahasa asing, maka tim dosen pun memutuskan bahwa pelatihan ini dikhususkan untuk meningkatkan keterampilan berbicara dalam Bahasa Inggris saja. Para peserta diajarkan untuk dapat mengucapkan kata dan kalimat Bahasa Inggris dengan benar dan menunjukan gesture yang tepat dalam berkomunikasi.

\section{Simpulan}

Secara keseluruhan pelaksanan kegiatan seminar dan pendampingan cukup memberikan hasil dimana para peserta hingga saat pendampingan terakhir sudah dapat berbicara menggunakan Bahasa Inggris dalam lingkup pengelolaan homestay. Tim dosen memberikan motivasi kepada peserta untuk terus menerus mempraktikan penggunaan Bahasa Inggris di rumah bersama dengan anggota keluarga lainnya. Selama masa pandemic covid 19 kedatangan tamu di Desa Liang Ndara memang menurun drastis, namun kondisi ini memberikan kesempatan bagi para pengelola homestay untuk berbenah diri baik dari lingkungan fisik maupun peningkatan kapasitas SDM pengelola homestay. Keberlangsungan keberadaan homestay ini sangat tergantung dari baik tidaknya kualitas SDM pengelolannya. Gencarnya bantuan yang diberikan pemerintah kepada para pengelola homestay harus diimbangi dengan pembangunan SDM. Pendampingan ini hendaknya dilanjutkan agar masyarakat tidak lupa dan menjadi terbiasa unuk berkomunikasi menggunakan Bahasa Inggris dengan wisatawan mancanegara. Pola yan terbiasa diharapkan dapat menjadi standar bagi pengelola homestay akan kemampuan berkomunikasi menggunakan Bahasa Inggris.

\section{Referensi}

Secretariat, A. S. E. A. N. (2016). ASEAN homestay standard. Jakarta: The ASEAN Secretariat.

Ismail, M. N. I., Hanafiah, M. H., Aminuddin, N., \& Mustafa, N. (2016). Community-based Homestay Service Quality, Visitor Satisfaction, and Behavioral Intention. Procedia - Social and Behavioral Sciences, 222, 398-405. Retrieved https://doi.org/10.1016/j.sbspro.2016.05.192

Kontogeorgopoulos, N., Churyen, A., \& Duangsaeng, V. (2015). Homestay Tourism and the 
Commercialization of the Rural Home in Thailand. Asia Pacific Journal of Tourism Research, 20(1), 29-50. Retrieved https://doi.org/10.1080/10941665.2013.852119

Topowijono, T. (2018). Penerapan Hygiene dan Sanitasi Dalam Upaya Peningkatan Mutu Kualitas Food and Baverage (Studi Pada Pantai Konang Desa Ngelebeng Kecamatan Panggul Kabupaten Trenggalek). Jurnal Administrasi Bisnis, 58(2), 146-154. Retrieved http://administrasibisnis.studentjournal.ub.ac.id/index.php/jab/article/view/2441

Draft Rencana Pariwisata Desa Liang Ndara. (2017). Created: Creative Entrepreneurship for Accelerating Tourism and Local Economic Development

Suherian, Herlan dan Yono Budhiono. (2013). Psikologi Pelayanan Di Bidang Pariwisata dan Hospitality serta di Berbagai Bidang Bisnis lainnya. Bandung: Media Perubahan.

Testiana, D. W., Mulyadi, D., \& Faturrahman, A. (2016). Peningkatan Kemampuan Berbahasa Inggris Dan Manajemen Pemasaran Melalui Web Bagi Pemilik Homestay Desa Wisata Kandri Semarang. Jurnal Abdimas, 20(1), 61-66. Retrieved https://journal.unnes.ac.id/nju/index.php/abdimas/article/view/7652 